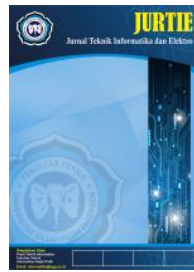

Jurnal JURTIE, Vol 4 No 1 Januari 2022 Hal 01-11

e-ISSN: 2809-7742; p-ISSN : 2809-770X

Received 14 November 2021 / Revised 3 Desember 2021 / Accepted 24 Desember 2021

Jurnal Teknik Elektro dan Informatika

https://jurnal.ugp.ac.id/index.php/jurtie

\title{
E-COMMERCE PENJUALAN KOPI GAYO (Studi Kasus : UMKM Ine Kupi di Kecamatan Bandar)
}

\author{
Ilham Mabrur ${ }^{1 *}$, Mahmuda Saputra², Hendry Syahputra ${ }^{3}$ \\ ${ }^{123}$ Program Studi S1 Teknik Informatika Fakultas Teknik, Universitas Gajah Putih, Kabupaten Aceh Tengah
}

\begin{abstract}
Bahasa Inggris\} E-Commerce is a flexible buying and selling system where a buyer does not need to come to a physical store to buy an item. Currently e-commerce is one of the alternative options for a business that is especially engaged in the field of processed coffee as a medium of information that facilitates interaction between sellers and buyers without limited space and time.

Coffee is one of the leading commodities in plantation subsectors in Indonesia, especially in the gayo karana highland area because it has good market opportunities at home and abroad and also has an important role in the Indonesian economy, one of which is the Ine kupi business owned by individuals who are on the main shah road, bahgie bertona village, Kec Bandar, Bener Meriah, Aceh where with the design of this sales e-commerce system can make it easier for consumers to order products on Ine Kupi as long as they are connected to the internet network, Consumers only need to register, login and place an order.
\end{abstract}

\section{Keywords: : E-Commerce, Kopi gayo, Ine Kupi}

Abstract.\{Bahasa Indonesia\} E-Commerce adalah sebuah sistem jual beli yang bersifat fleksibel dimana seorang pembeli tidak perlu datang ke suatu toko fisik untuk membeli suatu barang. Saat ini e-commerce merupakan salah satu alternatif pilihan untuk sebuah usaha yang khususnya bergerak di bidang olahan kopi sebagai media informasi yang memudahkan adanya interaksi antara penjual dan pembeli tanpa dibatasi ruang dan waktu.

Kopi merupakan salah satu komoditas unggulan dalam subsektor perkebunan di Indonesia khususnya di daerah dataran tinggi gayo karana karena memiliki peluang pasar yang baik di dalam negeri maupun luar negeri dan juga memiliki peran penting dalam perekonomian Indonesia salah satunya adalah usaha Ine kupi yang dimiliki oleh perorangan yang berada di jalan syah utama, desa bahgie bertona,Kec Bandar, Bener Meriah,Aceh dimana dengan di rancangya sistem e-commerce penjualan ini di dapat mempermudah konsumen dalam memesan produk pada Ine Kupi selama yang terhubung dengan jaringan internet, konsumen hanya perlu mendaftar, melakukan login dan melakukan pemesanan.

Keywords: E-Commerce, Kopi gayo, Ine Kupi

\section{Pendahuluan}

E-Commerce adalah sebuah sistem jual beli yang bersifat fleksibel dimana seorang pembeli tidak perlu datang ke suatu toko fisik untuk membeli suatu barang. Saat ini ecommerce merupakan salah satu alternatif pilihan untuk sebuah usaha yang khususnya

*Corresponding author's email: name@ai.ue.oa, Tel.: +00-00-000000; fax: +00-00-000000 doi: 10.14716/ijtech.v0i0.0000 
bergerak di bidang olahan kopi sebagai media informasi yang memudahkan adanya interaksi antara penjual dan pembeli tanpa dibatasi ruang dan waktu. Dengan didukung oleh perkembangan teknologi informasi yang semakin canggih dan mudah didapat perkembangan e-commerce pun semakin bertambah dan semakin diminati banyak usaha di Indonesia yang khususnya merupakan satu negara yang memiliki penikmat kopi yang besar dan juga Indonesia memiliki beberapa paritas kopi di antaranya kopi gayo yang merupakan khas dari dataran tinggi gayo.

Kopi merupakan salah satu komoditas unggulan dalam subsektor perkebunan di Indonesia khususnya di daerah dataran tinggi gayo karana karena memiliki peluang pasar yang baik di dalam negeri maupun luar negeri dan juga memiliki peran penting dalam perekonomian Indonesia, baik sebagai sumber perolehan devisa maupun sumber kehidupan petaninya. Konsumsi kopi meningkat daritahun ke tahun sehingga peningkatan produksi kopi di Indonesia memiliki peluang yang cukup besar untuk melakukan penjualan hasil olahan kopi khusunya olah kopi gayo di mana merupakan salah satu kopi khas nusantara asal gayo yang cukup banyak digemari oleh berbagai kalangan di dunia. Kopi gayo memiliki aroma dan rasa yang sangat khas di mana memiliki cita rasa kopi yang harum dan rasa gurih hampir tidak pahit. Kopi gayo aceh gayo dihasilkan dari perkebunan rakyat di dataran tinggi gayo.

Ine kupi adalah usaha rumahan yang bergeraka pada pengolah kopi gayo menjadi bubuk siap seduh, Ine kupi juga merupakan usaha yang melakukan penjuaan olahan kopi secara offline. Ine kupi merupakan umkm usaha yang bergerak pada penjulan bubuk kopi berkualiatas yang berasal dari Bener Meriah dan berdiri pada tahun 2020 dengan mempekerjakan beberapa karyawan, Pemasaraan produk ine kupi untuk sekarang ini masih sebatas wilayah Bener Meriah saja oleh karena itu perlu dibuat sebuah sistem informasi penjualan barang berbasis web ( e-commerce ) untuk meningkatkan dan menjangkau konsumen luas yang serba digital untuk sekarang ini.

Maka, atas dasar permasalahan ini penulis mengusulkan pembangunan sistem informasi penjualan bubuk kopi pada ine kupi berbasis web (e-commerce) untuk meningkatkan penjualan dan menjangkau konsumen luas yang serba digital yang bertujuan untuk memudahkan penikmat kopi dalam membeli kopi tanpa harus datang langsung ke toko ine untuk membeli.

\section{Tinjauan Pustaka}

Menurut Rohmat Taufik, dkk. 2020, "Analisis Dan Perancangan Sistem Informasi Monitoring Quality Control Produksi Makanan Pada Pt. Ultra Prima Abad" menjelaskan Rancangan sistem informasi monitoring quality control dan defective produksi yang diusulkan dapat memberikan kemudahan bagi pimpinan untuk memonitoring quality control dan defective produksi. Metode yang dipakai menggunakan PIEC ESdan Analisa defective Unified Modelling

Menurut Anwardi, dkk. 2020 Analisis PIECES dan Pengaruh Perancangan Website Fikri Karya Gemilang Terhadap Sistem Promosi Menggunakan Model Waterfall Perancangan website menggunakan model waterfall dengan tingkat usability website berada pada kategori good. Hal ini membuktikan bahwa menurut penilaian pengguna, website sudah memberikan kenyamanan antarmuka yang dikategorikan good. Berdasarkan hasil analisis PIECES sistem usulan terdapat nilai rata rata tingkat kepuasan konsumen sebesar 4,15 yang berarti penilaian konsumen sudah cukup memuaskan dengan menggunakan sistem promosi usulan yang diharapkan dapat memberikan dampak yang 
signifikan terhadap pedapatan perusahaan di masa akan datang Metode PIECES dan Model Waterfall

Ari Wibowo. 2020 "Analisa dan perancangan sistem informasi inventory penjualan dan pembelian perangkat komputer berbasis web (studi kasus: PT. Stefan Mandiri Perkasa)" dikembangkan lagi menjadi aplikasi berbasis web yang mana dapat digunakan oleh staff gudang, staff penjualan dan staff pembelian dalam menjalankan proses bisnis membantu membuat laporan hingga pengelolaan data barang pada PT. Stefan Mandiri Perkasa.

Ita Dewi Sintawati dan Tri Hartati. 2020 "Analisa metode pieces untuk sistem penjualan alat proteksi radiasi pada CV. Kashelara Jakarta". Dari hasil analisa sistem berjalan menggunakan metode PIECES ini tidak layak, karena sistem manual sangat banyak sekali kelemahannya. Dengan Manfaat yang didapatkandengan dibuat-kannya system.

Untuk menghasilkan suatu pelayanan publik yang berkualitas pinstansi atau organisasi, dalam hal ini harus mampu sejalan dengan perkembangan teknologi modern. Karena dengan masuknya teknologi modernisasi yang berbasiskan komputerisasi maka kinerja pemerintah dapat berjalan lebih optimal sehingga pelanan publik pun terpenuhi dengan baik. Untuk itulah pemerintah harus mampu mengembangkan sistem yang dapat menunjang kinerja yang berorientasikan pada media komputerisasi. Namun, harus ditekankan bahwa suatu sistem selalu dihadapkan dengan berbagai permasalahan yang ada didalamnya. Untuk itu pemerintah harus dapat meminimalisir permasalahan bahkan menyelesaikan permasalahan tersebut. Untuk menyelesaikan permasalahan - permasalah tersebut dapat dilakukan dengan menganalisis keadaan sistem tersebut baik yang akan dibangun maupun yang telah dibangun.

Analisis PIECES (Performance, Information, Economy, control, Eficiency, dan Service) merupakan teknik untuk mengidentifikasi dan memecahkan. permasalahan yang terjadi pada sistem informasi. Dari analisis ini akan menghasilkan identifikasi masalah utama dari suatu sistem serta memberikan solusi dari permasalahan tersebut.

Ine kupi adalah sebuah kedai kopi yang dimiliki oleh perorangan yang berada di jalan syah utama, desa bahgie bertona,kec bandar, BENER MERIAH,ACEH. Ine kupi dilengkapi dengan berbagai fasilitas, seperti tersedianya wifi yang bisa diakses oleh pelanggan secara gratis dan tempat yang nyaman, selain itu ine kupi juga mempunyai beberapa jenis bubuk kopi yang biji nya di procces secara baik di antara nya full wash,natural,wine,dan sebagai nya.

E-commerce merupakan suatu tindakan melakukan transaksi bisnis secara elektronik dengan menggunakan internet sebagai media komunikasi yang paling utama. Penyediaan website dan metode pembayaran, kegiatan E-commerce bisa dibedakan menjadi dua, yaitu E-commerce sederhana dan E-commerce otomat. Secara sederhana, website untuk kegiatan E-commerce menggunakan sistem statis ataupun shopping cart sederhana yang berguna untuk mengumpulkan daftar order dari pembeli. Selanjutnya proses transaksi melalui email dan menggunakan bank sebagai transaksi finalnya. Sedangkan semua kegiatan order dan pembayaran dilakukan secara terintegrasi (otomatis) melalui website, sehingga pemilik website hanya mengatur pengemasan produk dan mengirimkannya kepada pembeli (W Saputro, 2009). E-commerce tersedia suatu integrasi rantai nilai dari infrastrukturnya, yang terdiri dari tiga lapis. Pertama, infrastruktur sistem distribusi (flow of good) kedua, infrastruktur pembayaran (flow of money) dan ketiga, infrastruktur sistem informasi (flow of information). 
Proses pembayaran e-commerce cukup rumit karena banyaknya jenis alternatif debit dan keredit serta lembaga keuangan dan perantara yang menjadi bagian dari proses tersebut di antara proses pembayaran tersebut (Humdiana dan Indriyani, 2005)

\section{Metode Penelitian}

\subsection{Analisa Sistem Yang Diusulkan}

Prosedur yang diusulkan diartikan sebagai prosedur yang akan di rancang untuk kedepannya, seperti mendefinisikan kebutuhan-kebutuhan fungsional dari prosedur sehingga dapat diketahui apa saja kebutuhan - kebutuhan pengguna yang belum terpenuhi oleh sistem yang sedang berjalan tersebut. Adapun langkah-langkah prosedur yang diusulkan Sistem e-commerce yang di usulkan adalah sebagai berikut :

1. Merancang sebuah sistem penjualan produk kopi gayo pada usaha UMKM Ine kupi berbasis web dengan bentuk pemodelan menggunakan bahasa pemograman HTML dan PHP dalam pembuatan web serta mengunakan MySQL sebagai database.

2. Sistem yang di usulkan dalam ini di mulai dari konsumen melihat produk-produk terbaru dari Toko Ine Kopi maka dapat mengakses web ini tanpa perlu menjadi anggota.

3. Konsumen memesan produk barang makan harus mendaftar menjadi Konsumen terlebih dahulu, setelah login menjadi Konsumen maka Konsumen berhak memesan barang.

4. Cara pembayaran harus di lakukan dengan cara mentransfer uang ke rekening Bank Toko Ine Kopi. Setelah mentransfer Konsumen meberitahukan bukti transfer, dengan cara menginput bukti pembayaran ke dalam fomulir sistem. Transfer paling lambat 24 Jam dari tanggal pesan, jika tidak mentransfer maka pesanan akan dianggap batal.

5. Pengiriman barang akan dikirim jika Konsumen sudah mentransfer uang, setelah itu barang akan di kirim ke alamat yang sudah di isikan oleh Konsumen dengan jasa kurir.

\subsection{Analisis PIECES}

Pada sistem penjualan yang lama merupakan sebuah sistem manual yang belum terkomputerisasi dan sangat sulit untuk mengetahui informasi tentang produk yang terjual oleh usaha tersebut. sehingga dala mengetahui informasi tentang usaha kecil tidak dapat disajikan dengan cepat dan akurat.

Untuk mengidentifikasi masalah tersebut secara tepat dan jelas digunakan sebuah paduan analisis PIECES (performance, information, economy, control, efiency, dan services) untuk menganalisis kinerja, informasi, ekonomi, keamanan aplikasi, efisiensi, dan pelayanan.

\section{Hasil Pembahasan}

Berikut adalah implementasi program sesuai dengan rancangan yang sebelumnya telah dibuat, antara lain :

1. Implementasi Program Administrator 
1) From Login

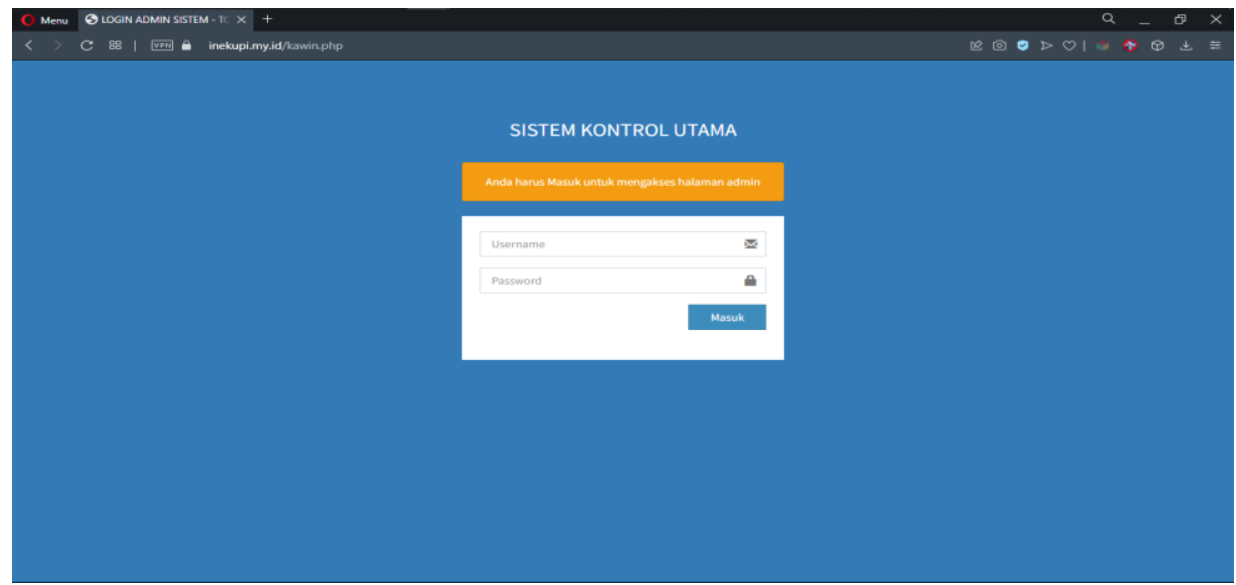

Gambar 1 Form Login Admin

2) From Input Barang Admin

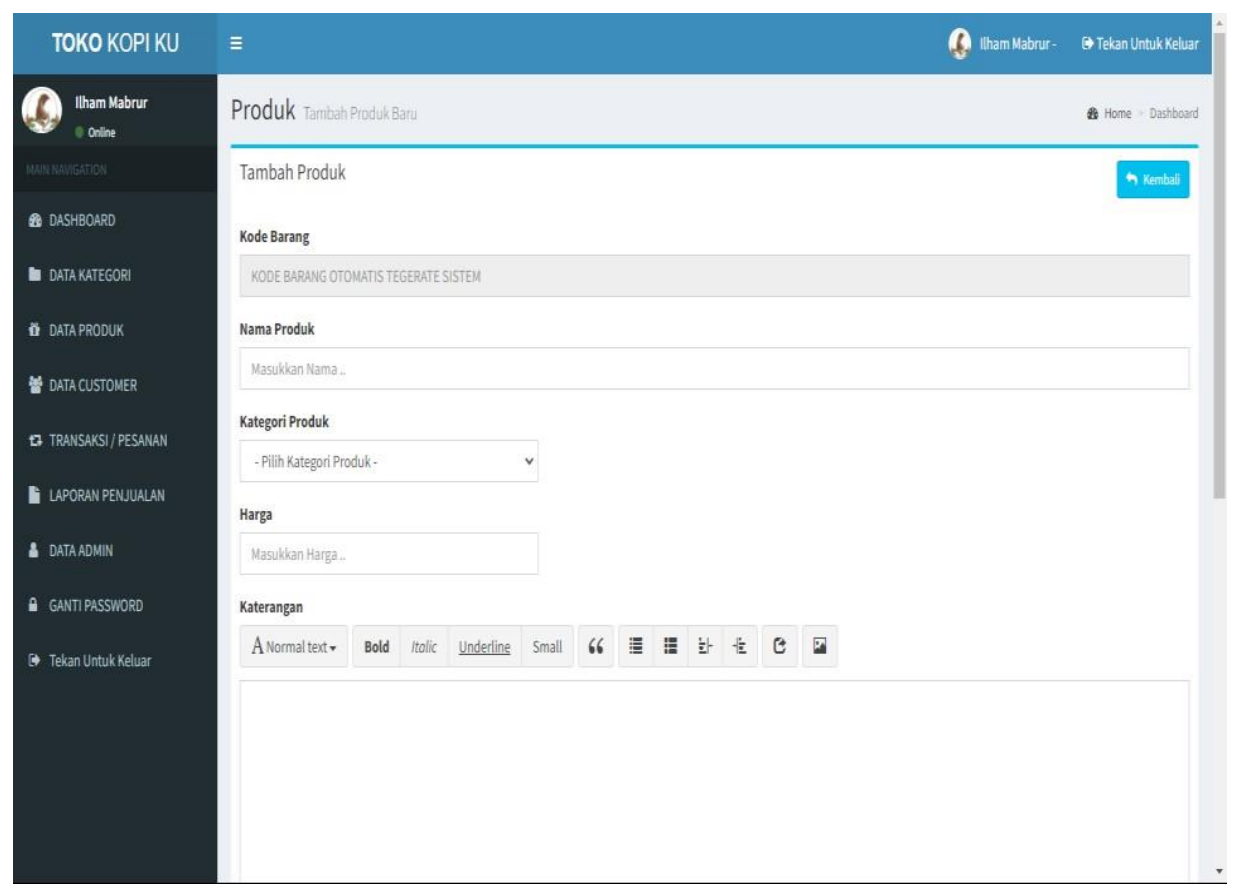

Gambar 2 Form Input Barang 


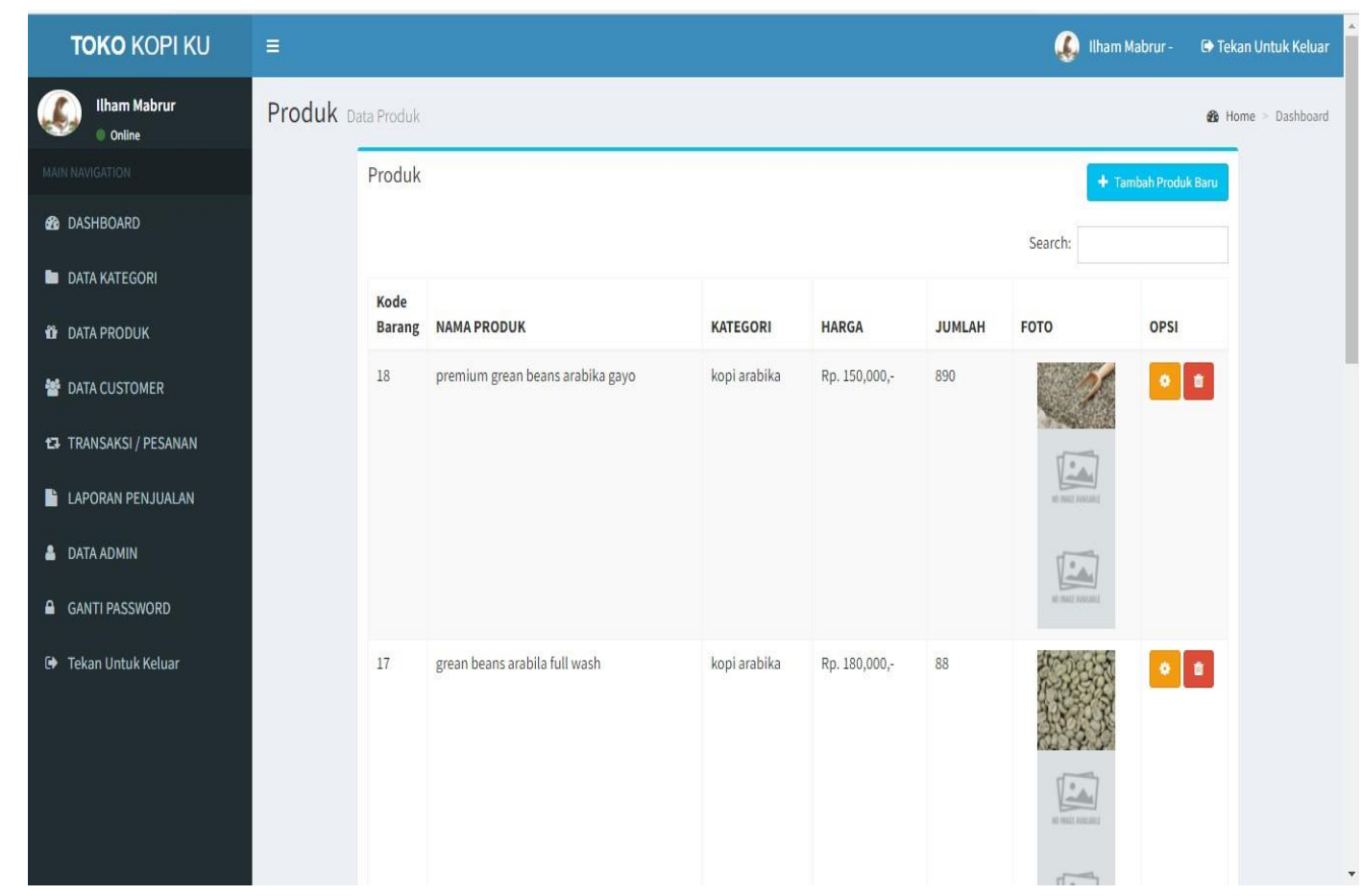

Gambar 3 Form Input Barang

3) From Konfimasi Pesanan admin

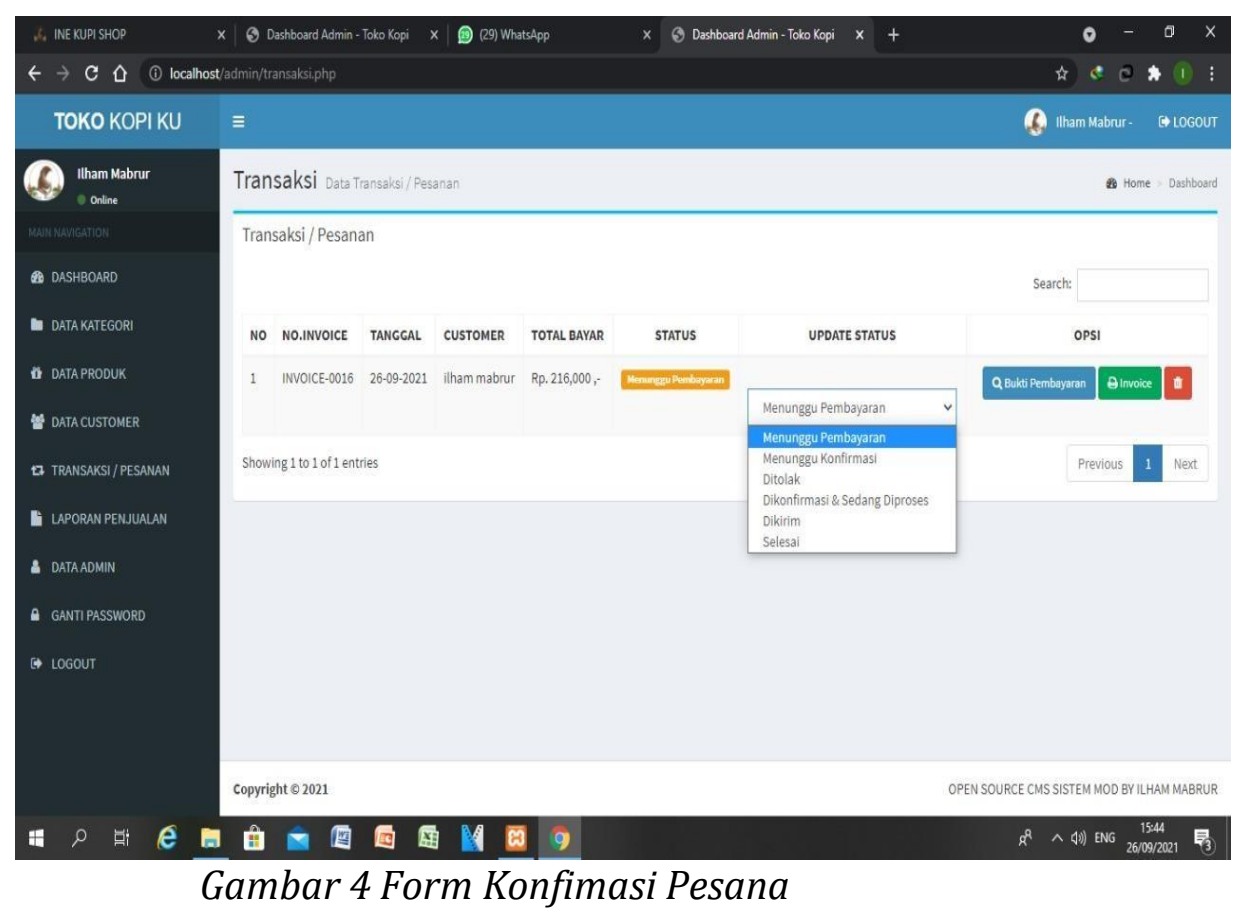

2. Implementasi Program Pengguna

1) Tampilan Halaman Baranda Pengguna 




\section{Gambar 5 Halaman Barada}

2) Halaman Pemesanan Produk

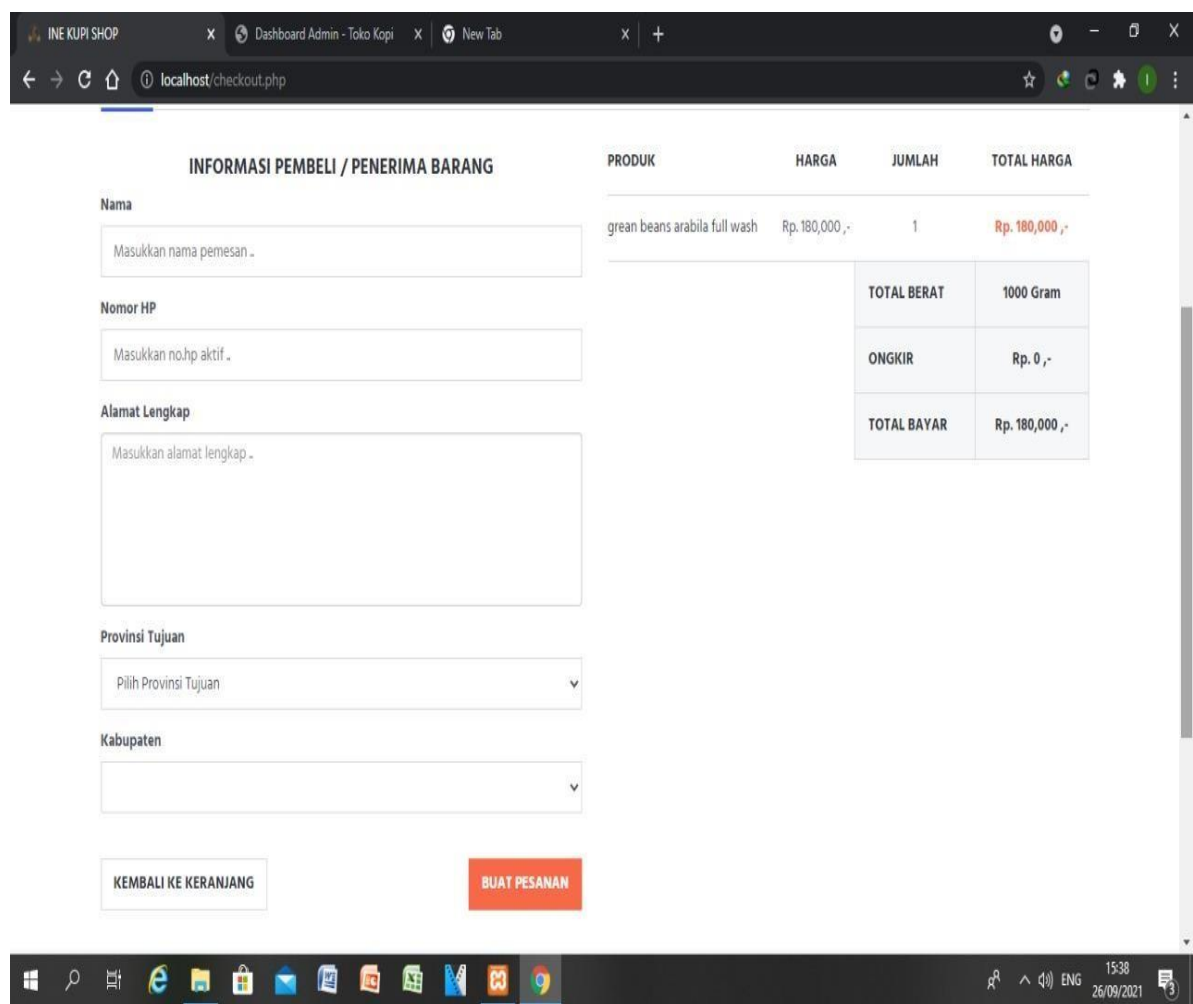

Gambar 6 Halaman Pemesanan 
3) Halaman Pembayaran

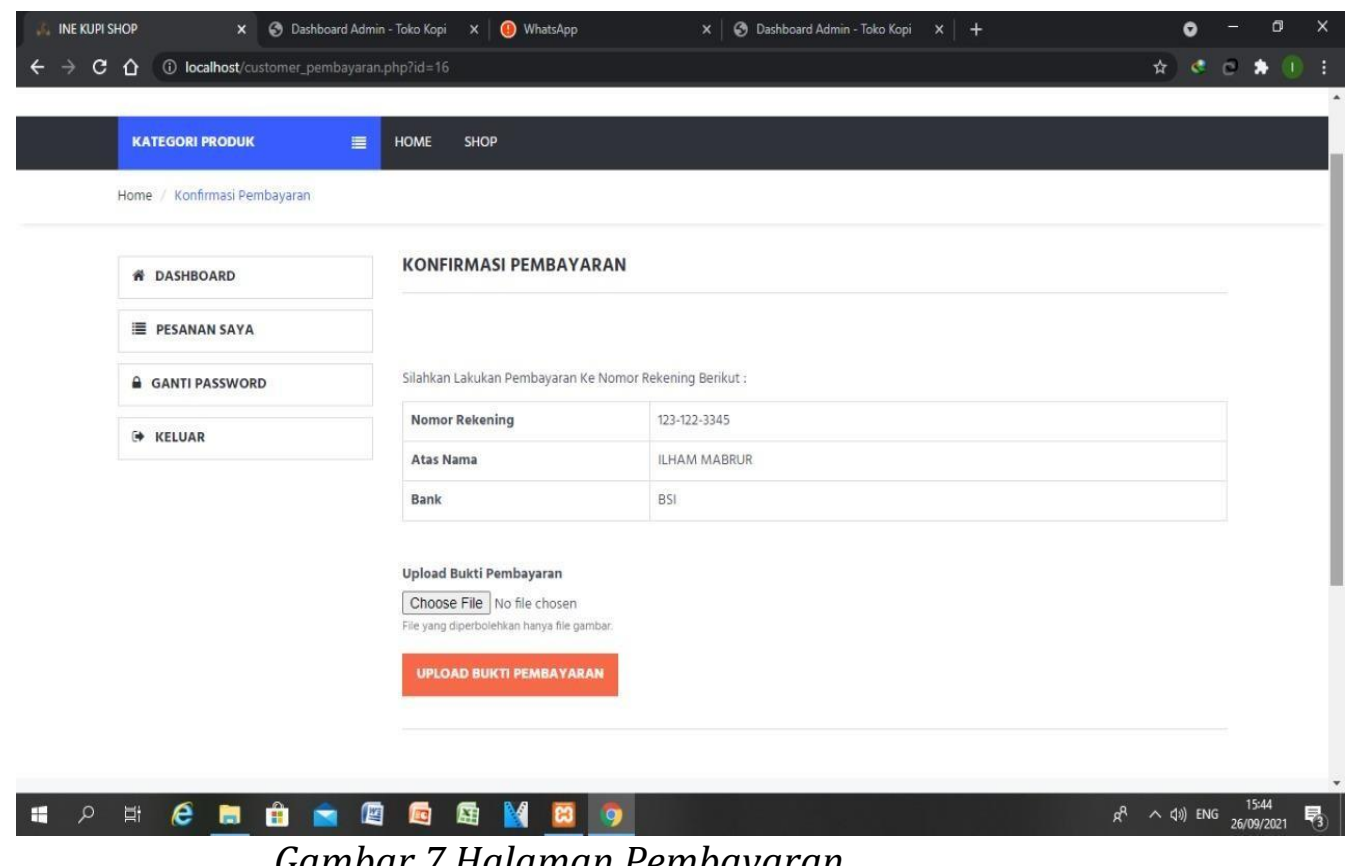

Gambar 7 Halaman Pembayaran

4) Halaman Status Pesanan

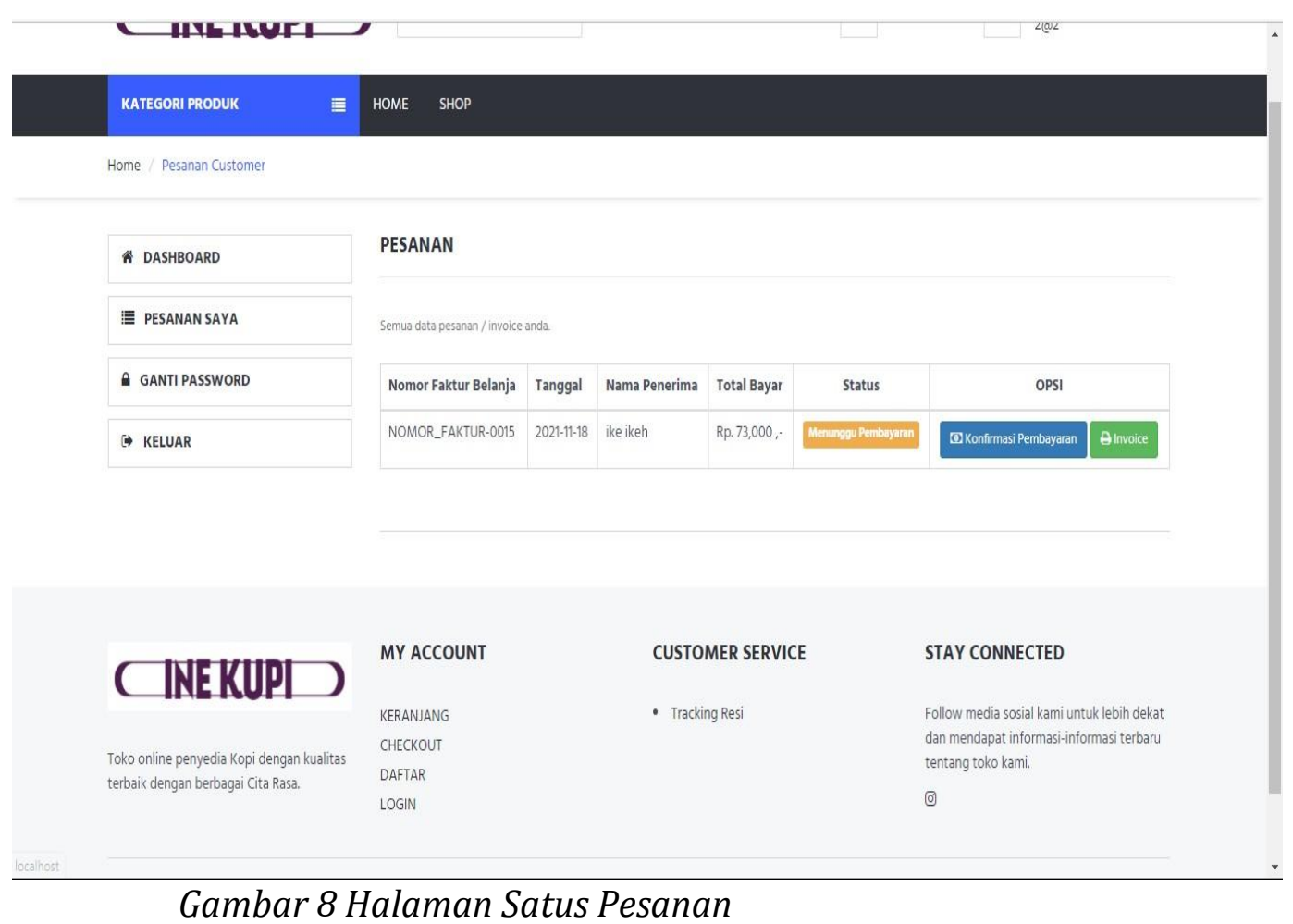

\subsection{Pengujian Sistem}

Pengujian dilakukan dengan menjalankan serangkaian scenario pengujian. Pengujian dilakukan menggunakan blackbox testing dengan 
memfokuskan pada input,output dan fungsi dasar dari aplikasi. Skenario pengujian dilakukan dalam pada prosespengembangan

1. Rencana Pengujian

Pengujian ini merupakan pengujian elemen-elemen fungsional tanpa menguji desain dan kode program. Rencana pengujiannya dapat dilihat pada tabelberikut :

\begin{tabular}{|c|c|c|}
\hline Item Uji & Pengujian & Jenis Uji \\
\hline Menu Daftar & Tambah data Pengguna & Black box \\
\hline \multirow{3}{*}{ Menu Login } & Verifiksi login pengguna & \multirow{3}{*}{ Black box } \\
\hline & $\begin{array}{l}\text { Verifiksi login Tes } \\
\text { pengguna }\end{array}$ & \\
\hline & Verifikasi pengguna admin & \\
\hline $\begin{array}{l}\text { Menu Input } \\
\text { Produk }\end{array}$ & Tambah data produk & Black box \\
\hline Menu Pesanan & $\begin{array}{l}\text { Tambah Pemebelian } \\
\text { Produk }\end{array}$ & Black box \\
\hline
\end{tabular}

Tabel 1 Rencana pengujian sistem

2. Hasil Pengujian

Berdasarakan rencana pengujian yang telah disusun, maka dapatdilakukan pengujian dengan menggunakan metode Blackbox.

\begin{tabular}{|c|c|c|c|c|}
\hline No & $\begin{array}{l}\text { Kasus } \\
/ \\
\text { Diuji }\end{array}$ & Skenario Uji & $\begin{array}{l}\text { Hasil Yang } \\
\text { Diharapkan }\end{array}$ & Hasi Pengujian \\
\hline 1 & $\begin{array}{l}\text { Menu } \\
\text { Daftar }\end{array}$ & $\begin{array}{l}\text { Pengguna mengisi } \\
\text { data pendaftaran } \\
\text { dengan } \\
\text { memasukan } \\
\text { email, kata sandi } \\
\text { danverifikasi kata } \\
\text { sandi. }\end{array}$ & $\begin{array}{l}\text { Jika data input data } \\
\text { pendaftaran valid, } \\
\text { maka pengguna } \\
\text { akan diarahkan ke } \\
\text { halamanlogin }\end{array}$ & $\begin{array}{l}\text { [?] berhasil[ ] tdak } \\
\text { berhasil }\end{array}$ \\
\hline \multirow[t]{2}{*}{2} & \multirow[t]{2}{*}{ Menu Login } & $\begin{array}{l}\text { Pengguna } \\
\text { mengisi data } \\
\text { login pada from } \\
\text { login pengguna }\end{array}$ & $\begin{array}{l}\text { Jika data login valid, } \\
\text { maka pengguna } \\
\text { akan diarahkan ke } \\
\text { halamanKeranjang }\end{array}$ & $\begin{array}{l}\text { [?] berhasil[] tdak } \\
\text { berhasil }\end{array}$ \\
\hline & & $\begin{array}{l}\text { admin mengisi data } \\
\text { login pada from } \\
\text { loginkhusus admin }\end{array}$ & $\begin{array}{l}\text { Jika data login valid, } \\
\text { maka admin akan } \\
\text { diarahkan ke } \\
\text { dasboard }\end{array}$ & $\begin{array}{l}\text { [?] berhasil[] tdak } \\
\text { berhasil }\end{array}$ \\
\hline
\end{tabular}




\begin{tabular}{|c|c|c|c|c|}
\hline 3 & $\begin{array}{l}\text { Menu } \\
\text { Input } \\
\text { Produk }\end{array}$ & $\begin{array}{l}\text { Admin } \\
\text { Mengimput } \\
\text { Produk }\end{array}$ & $\begin{array}{l}\text { Jika input data } \\
\text { berhasil,maka } \\
\text { diarahkan ke } \\
\text { halaman Daftar } \\
\text { Produk }\end{array}$ & $\begin{array}{l}{[\text { []] berhasil[ ] tdak }} \\
\text { berhasil }\end{array}$ \\
\hline 4 & Menu Beli & $\begin{array}{l}\text { Pengguna } \\
\text { MemilihProduk }\end{array}$ & $\begin{array}{l}\text { Jika berhasil } \\
\text { akan diarahkan } \\
\text { kemenubayar }\end{array}$ & $\begin{array}{l}\text { [?] berhasil[ ] tdak } \\
\text { berhasil }\end{array}$ \\
\hline 5 & $\begin{array}{l}\text { Menu } \\
\text { Kofirma } \\
\text { siBayar }\end{array}$ & $\begin{array}{l}\text { Admin megubah } \\
\text { stauspembayaran }\end{array}$ & $\begin{array}{l}\text { Jika input jawaban } \\
\text { berhasil, maka akan } \\
\text { diarahkan ke } \\
\text { halaman } \\
\text { daftar pembeli }\end{array}$ & $\begin{array}{l}{[\text { [?] berhasil[ ] tdak }} \\
\text { berhasil }\end{array}$ \\
\hline 10 & $\begin{array}{l}\text { Menu } \\
\text { Pengolah } \\
\text { andata } \\
\text { pengguna } \\
\text { (admin) }\end{array}$ & $\begin{array}{l}\text { Admin } \\
\text { memilih } \\
\text { tombol blok }\end{array}$ & $\begin{array}{l}\text { Jika berhasil di klik, } \\
\text { maka status } \\
\text { penggunaakan } \\
\text { terblokir }\end{array}$ & $\begin{array}{l}{[\text { [?] berhasil[ ] tdak }} \\
\text { berhasil }\end{array}$ \\
\hline
\end{tabular}

Tabel 2 hasil pengujian sistem

\section{Kesimpulan Hasil Pengujian}

Berdasarkan hasil pengujian alpha dengan kasus uji sample diatas yang menggunakan metoda Blackbox, secara keseluruhan pada tiap tampilan hasil dari pengujian ini dapat dikatakan berhasil atau diterima. Karena secara fungsional sistem sudah dapat bekerja dan menghasilkan output yang diharapkan dan layak dipergunakan.

\subsection{Kesimpulan}

Setelah melakukan analisa dan pengamatan secara langsung terhadap objek penelitian, maka penulis dapat menarik kesimpulan sebagai berikut :

1. Konsumen dapat memesan produk pada usaha UMKM Ine Kupi selama yang masih terhubung dengan jaringan internet, konsumen hanya perlu mendaftar, melakukan login dan melakukan pemesanan.

2. Sistem informasi penjualan produk yang di usulkan telah memenuhi fungsi- fungsi yang di harapkan, seperti pengolahan data barang dan penjualan barang.

3. Pada implementasi sistem aplikasi ini dapat dijalankan secara online.

\subsection{Saran}

Karena proses dalam pembuatan program aplikasi sistem informasi penjualanini masih ada kekurangannya dan masih jauh dari sempurna. Saran-saran yang diajukan untuk pengembangan berikutnya diantara lain :

1. Pengembangan informasi produk yang up to date untuk konsumen.

2. Pengamanan data dengan melakukan pem-backup-an data-data yang sangat penting secara terus menerus agar data tersebut terhindar dari segala kerusakan atau kehilangan. 
3. Perlunya peningkatan keamanan sistem dalam proses transaksi.

\section{References}

Jogiyanto. 2005. Analisis dan Desain Sistem Informasi. Yogyakarta: PenerbitAndi Indrajit, 2001, Analisis dan Perancangan Sistem Berorientasi Object.Bandung, Informatika. Lani Sidharta. (1995). Pengantar Sistem Informasi Bisnis. Jakarta: PT. Elex Media Komputindo.

Murdick, R.G, “ Definisi Sistem”, (1991:27)

Wahyono, Teguh. Sistem Informasi (Konsep Dasar, Analisis, Desain danImplementasi). Graha Ilmu, Yogyakarta, 2004.

Fitzgerald, Jerry. FitzGerald, Ardra F. and Stalling Jr, Warren D. (1981) Fundamentals Of System Analysis, Edisi kedua, John Willey \& Sons, New York.

Whitten, Jeffrey L, et al, Metode Desain \& Analisis Sistem, Edisi 6, Edisi International, Mc GrawHill, ANDI, Yogyakarta: 2004

McLeod Raymond, Schell George. 2004. Sistem Informasi Manajemen Edisike-8. Jakarta: PT. Indeks

Humdiana dan Evi Indrayani. 2006. Sistem Informasi Manajemen Obsesi Mengoptimalkan Informasi Dalam Bisnis. Graha Ilmu. Yogyakarta.

Nugroho, adi. 2006. E-Commerce Memahami perdagangan Moderen diDunia Maya. Bandung: Informatika.

Saputro, 2009, E-commerce, Pilihan Wirausaha Modern. Andi,Yogyakarta.

Asnawi dan Wijaya. 2008. Metodologi Penelitian Keuangan, Prosedur, Ide,dan Kontrol. Edisi Pertama. Yogyakarta: Graha Ilmu

Humdiana, \& Indriyani, E. (2005). Sistem Informasi Manajemen. Yogyakarta: Graha Ilmu.

Adisasmita, H. Rahardjo. 2005. Dasar-Dasar Ekonomi Wilayah. Grahallmu, Yogyakarta 